\title{
CORRESPONDENCE
}

\section{A nurse-led multidisciplinary COPD programme: potential flaws in the results?}

\section{Dear Sirs,}

We read with interest the paper by Zakrisson et al.' on a nurse-led multidisciplinary programme (NMP) for primary care COPD patients initially published online and now on page 427 of this issue of the PCRJ. The authors report a significant reduction in exacerbation frequency after one year, but no changes in quality of life or functional capacity. However, we have noticed some rather surprising and relevant inaccuracies that may have flawed the results and conclusions. Thus, we feel obliged to point these out in the hope that the authors can clarify the definitive results.

First, the authors state that they have investigated the effects of NMP, especially in patients with GOLD stages 2 and 3. According to GOLD criteria, these patients are defined as having a post-bronchodilator $\mathrm{FEV}_{1}$ between $30-80 \%$ of predicted. ${ }^{2}$ However, for reasons that are unclear, the authors applied a strict inclusion criterion of $\mathrm{FEV}_{1} 40-59 \%$ of predicted, in addition to an age criterion of 60-75 yrs. As a result, unfortunately they were able to include a mere $9.6 \%$ of their eligible patients (176 out of 1828), not only leading to a highly underpowered study, but also making it hard to interpret the results since external validity was starkly reduced. In earlier reports, it has been demonstrated that the greatest room for improvement in primary care patients can be expected in those with tangible dyspnoea and impaired health status (MRC score $>2$ and/or CCQ score >1) across all GOLD stages. ${ }^{3.4}$ Therefore, it would have made more sense to apply broader inclusion criteria for a primary care NMP, with a focus on those patients with elevated MRC and CCQ scores at baseline.

The most prominent differences in quality of life and exercise tolerance in Zakrisson et al.'s study were reported after 2 months. This can be interpreted as an immediate benefit of the NMP program, which lasted 6 weeks. It would be interesting to compare the CCQ score with the control group at 2 months; however, these data are not shown. Furthermore, it is unclear in what way the follow-up of the intervention group was arranged, and if, for example, any advice was provided to continue exercise training in the home-setting. This could have sustained the effect after 5 and 12 months in the intervention group. ${ }^{3}$

Finally, the authors seem to present a number of conflicting results in their tables. In table 2, the authors report a mean CCQ score at both baseline and 1 year follow-up of 2.0 in both control and intervention groups (so no change in any group), whilst in table 4 and 5 , the difference in CCQ score after 1 year amounts to 0.3 , again both in control and intervention groups. To our best understanding, this should have led to a mean CCQ of 1.7 in table 2, which needs to be clarified by the authors. Overall, the reported figures are strikingly similar across groups, while p-values do seem to differ. This raises the question: are the tables accurate? Apart from the confusing presentation of data, what does the reported difference of 0.3 in CCQ score actually mean? In the discussion section, Zakrisson et al. refer to a minimal clinically important difference (MCID) for the CCQ of 0.5 ; this is simply incorrect, ${ }^{5}$ as the
MCID for CCQ has been demonstrated to be 0.4 - which obviously comes closer to the reported difference of 0.3 in table 4 .

So, the question remains: is a multidisciplinary COPD programme effective in primary care? In addition to the authors addressing the flaws mentioned above, we would suggest a reanalysis of the dataset taking the aforementioned suggestions into account, as we think this would significantly aid interpretation of their results. In our opinion, it might be that the authors could reach other conclusions. This study potentially provides insight into an area which is hitherto largely under-reported, but more studies of sufficient quality are required to demonstrate whether multidisciplinary COPD programmes are effective in primary care.

\section{Annemarije L Kruis ${ }^{\mathrm{a}}$, Niels H Chavannes ${ }^{\mathrm{a}}$}

a Department of Public Health and Primary Care, Leiden University Medical Center, The Netherlands

\section{*Correspondence: E-mail: n.h.chavannes@lumc.nl}

Received 7th July 2011; accepted 8th July 2011; online 19th October 2011

Conflicts of interest

The authors declare that they have no conflicts of interest in relation to this article.

\section{References}

1. Zakrisson $A B$, Engfeldt $P$, Hagglund $D$, et al. Nurse-led multidisciplinary programme for patients with COPD in primary health care: a controlled trial. Prim Care Respir J 2011; 20(4):427-33. http://dx.doi.org/10.4104/pcrj.2011.00060

2. GOLD. Global strategy for the diagnosis, management, and prevention of chronic obstructive pulmonary disease. 2009

3. Kruis AL, van AJ, Erkelens MR, et al. Sustained effects of integrated COPD management on health status and exercise capacity in primary care patients. Int I Chron Obstruct Pulmon Dis 2010;5:407-13.

4. Chavannes NH, Grijsen M, van den Akker M, et al. Integrated disease management improves one-year quality of life in primary care COPD patients: a controlled clinical trial. Prim Care Respir J 2009;18(3):171-76.

5. Kocks JW, Tuinenga MG, Uil SM, van den Berg JW, Stahl E, van der Molen T. Health status measurement in COPD: the minimal clinically important difference of the clinical COPD questionnaire. Respir Res 2006;7:62. http://dx.doi.org/10.1186/1465-9921-7-62

(C) 2011 Primary Care Respiratory Society UK. All rights reserved.

http://dx.doi.org/10.4104/pcrj.2011.00084

\section{Authors' reply}

Dear Sirs,

We are delighted to have this opportunity to respond to the concerns expressed by Chavannes and Kruis after our article (in this issue') was published online ahead of print in June.

As regards GOLD stages; when formulating the study design in 2005 there were other criteria in Sweden for the different COPD severity stages. ${ }^{2}$ At that time stage 3 was $\mathrm{FEV}_{1}$ 40\%-59\% predicted. When we sought ethical approval for the study we aimed to include stage 3 patients since it was recommended they should be offered pulmonary rehabilitation in guidelines at that time. ${ }^{2}$ After ethical approval was granted in 2006, the severity criteria in Sweden were changed to follow GOLD criteria - i.e. stage $2 \mathrm{FEV}_{1} 50 \%$ - 80\%, and stage $3 \mathrm{FEV}_{1} 30 \%$ $50 \%{ }^{3}$ But we had to follow the ethical approval restrictions. Later 
guidelines ${ }^{4}$ state that pulmonary rehab can be valuable for all patients with respiratory symptoms that are associated with limited functional capacity or reduced QoL. If we had designed the study today we would have included the patients Chavannes and Kruis suggest, and we are aware that this is a further limitation of our study. But there was not only one cause for the few patients eligible for inclusion; there were also many patients in the patient registers that had no spirometry-verified COPD diagnosis, a common problem even internationally. However, we have in our article stated that it is low powered and that the results should be interpreted with caution.

Chavannes and Kruis are interested in data comparing the groups after two months. We discussed this when designing the study but we wanted the control group to have "usual care". We decided to exclude the 2 - and 5-month assessments because they would not have had more care than the other patients in "usual care" and this could have been a threat to the external validity by expectancy effects - i.e. that the participants may behave in a particular manner because they are aware of participation in a study (the Hawthorne effect). The intervention consisted of a 6-week programme and the patients were told to continue physical activity, but there was no further intervention after six weeks.

As regards concerns about the tables. We can see that the data could be misinterpreted. In table 2 the mean in total CCQ was 1.998 in the intervention group and 1.978 in the control group at base line and after one year 1.739 in the intervention group and 1.720 in the control group. We have rounded off the figures to aid readability. These decimals can also explain the different $p$-values in the tables.

The MCID for the CCQ is also queried. Perhaps we have misinterpreted the figures of MCID in our references but still there is nothing incorrect in the interpretation and conclusion of our study. Even if the MCID is calculated to 0.4 (according to the Kocks paper cited by Chavannes and Kruis - that we did not have access to at the time), the intervention group did reach MCID after two months but it did not persist during the year and the control group did not reach it at all after one year.

Like Chavannes and Kruis, for us the question still remains: is a multidisciplinary program effective in primary care? We have not been able to come to a conclusion in our paper due to there being no significant statistical difference in functional capacity or QoL between the intervention group and the control group. However, we remain of the belief that primary care is highly appropriate in managing COPD considering its co-morbidities, ${ }^{5}$ especially when healthcare professionals in primary care are generalists. But more research is needed on this topic.

\section{*Ann-Britt Zakrisson ${ }^{a}$, Peter Engfeldt ${ }^{\text {a }}$ on behalf of the authors \\ a Family Medicine Research Centre, Örebro University, Sweden \\ *Correspondence: E-mail: ann-britt.zakrisson@orebroll.se}

Submitted 10th October 2011; accepted 12th October 2011;

online 14th November 2011

\section{Conflicts of interest}

The authors declare that they have no conflicts of interest in relation to this article.

\section{References}

1. Zakrisson $A B$, Engfeldt $P$, Hägglund $D$, Odencrants $S$, Hasselgren $M$, Arne $M$, Theander K. Nurse-led multidisciplinary programme for patients with COPD in primary health care: a controlled trial. Prim Care Respir J 2011;20:427-33. http://dx.doi.org/10.4104/pcrj.2011.00060

2. Socialstyrelsen. Socialstyrelsens riktlinjer för vård av astma och kroniskt obstruktiv lungsjukdom (KOL): faktadokument och beslutsstöd för prioriteringar. [National Board of Health and Welfare guidelines in care of asthma and COPD: document of facts of support in decisions and priorities] [in Swedish] Stockholm: Socialstyrelsen; 2004.

3. GOLD. Executive Summary: Global Strategy for the Diagnosis, Management, and Prevention of COPD [homepage on the Internet]. NHLBINHO workshop report; 2010 [cited 201129 March]. Available from: http://www.goldcopd.com.

4. ATS/ERS. American Thoracic Society/European Respiratory Society statement on pulmonary rehabilitation. Am J Respir Crit Care Med 2006;173(12):1390-413. http://dx.doi.org/10.1164/rccm.200508-1211ST

5. van der Molen T. Co-morbidities of COPD in primary care: frequency, relation to COPD, and treatment consequences. Prim Care Respir J 2010;19(4):326-34. http://dx.doi.org/10.4104/pcrj.2010.00053

(C) 2011 Primary Care Respiratory Society UK. All rights reserved. http://dx.doi.org/10.4104/pcrj.2011.00084

\section{Editors' note}

The concerns expressed by Chavannes and Kruis regarding the tables in Zakrisson et al.'s paper were noted by the authors. With the editors' consent, the authors subsequently made some minor changes to the tables in their paper in an effort to clarify the points raised. It is the corrected version of the Zakrisson et al. paper which appears in this issue of the $P C R J$, both online and in the hard copy version.

We are grateful to Chavannes and Kruis for raising these points, and welcome any correspondence of this nature regarding papers published online ahead of print on the PCRJ website (www.thepcrj.org). 